\title{
Disease modifying treatments and symptomatic drugs for cognitive impairment in multiple sclerosis: where do we stand?
}

\author{
Claudia Niccolai ${ }^{*} \mathbb{D}$, Benedetta Goretti and Maria Pia Amato
}

\begin{abstract}
Cognitive dysfunction is frequent in multiple sclerosis patients and has important and negative consequences for daily activities and quality of life of subjects. Disease modifying treatments for multiple sclerosis reduce the incidence of relapses and may prevent disease progression, but the influence on cognitive impairment is unclear, due to several limitations of the available studies. Moreover, symptomatic drugs for the improvement of already established cognitive deficits have been tested in small pilot studies, providing conflicting or mainly negative results. Currently, specific pharmacological therapies for the management of cognitive deficits in MS have not yet been developed. We will provide an updated overview of available evidence of pharmacological approaches for ameliorating cognitive deficits, based either on disease modifying treatments or symptomatic drugs.
\end{abstract}

Keywords: Pharmacological treatment, Cognitive impairment, Multiple sclerosis

\section{Background}

Cognitive impairment (CI) in multiple sclerosis (MS) affects about $40-70 \%$ of patients. It involves all the disease subtypes, sometimes from the early stages of the disease, also independently from physical disability. It has a negative impact on patient daily life, employment and on the capacity to benefit from in-patient rehabilitation [1]. Therefore, to improve patient function and quality of life, interventions to ameliorate or reduce CI are of paramount importance, through pharmacological and/or rehabilitation approaches. We will review available evidence on pharmacological approaches for $\mathrm{CI}$ in MS, based either on disease modifying treatments (DMT) or symptomatic drugs.

\section{Disease modifying treatments}

Since 1990s, DMTs are usually employed in clinical practice to reduce the incidence of relapses and disability progression in MS. The possible positive effect on cognitive outcomes can be due to the decrease of the ongoing

\footnotetext{
* Correspondence: claunicco@libero.it

Department of NEUROFARBA, University of Florence, Viale Pieraccini 6, Florence 50134, Italy
}

inflammatory activity, which may contribute to better cognitive performances. DMTs can also positively influence the cognitive performances, by acting on some key pathogenic mechanisms of MS-related cognitive impairment. In particular, all the approved DMTs reduce the accumulation of T2 and T1 lesions in the brain, and some of them also reduce the progression of brain atrophy. Moreover, some of the DMTs may also produce a neuroprotective effect via different mechanisms of action, such as through the delivery of neurotrophic factors or newer mechanism of action for newer drugs [2]. However, the interpretation of available data is complicated, due to methodological problems of study design and execution [1].

The bulk of available evidence for the effects of DMTs on cognitive outcomes in MS has been collected with the interferons (IFNB-1a and IFNB-1b).

Fisher et al. [3] have published an extensive study, exploring the effects of IFN b-1a on cognition, assessed by Multiple Sclerosis Functional Composite (MSFC) administered to 166 relapsing-remitting multiple sclerosis (RRMS) patients, in the context of a multicenter, 2-year, phase III randomized clinical trial. After two years, 
adjusting for baseline performance, IFN b-1a showed a significant beneficial effect on tests of information processing speed, learning and memory, as well as a positive trend on tests of visuospatial abilities and problem solving. Although it is difficult to generalize the trial results to everyday practice, due to the extensive neuropsychological assessment, the trial showed an improvement in cognitive performance in both arms, possibly due to "practice effects", which was however significantly more pronounced in the treatment group. The treatment arm also exhibited a significantly increased time to sustained deterioration in the performance on the Paced Auditory Serial Addition Test (PASAT).

The BENEFIT (Betaferon/Betaseron in Newly Emerging MS for Initial Treatment) trial and its extension at 3 and 5 years [4-6], underline the effect of IFNB-1b on cognition in patients with clinically isolated syndromes (CIS). In these trials, patients were randomized to receive IFNB-1b immediately after the clinical event or at the end of the trial. The results showed an improvement on cognitive performance in the PASAT over the five years, whose scores were in the normal range in the majority of the subjects at baseline. Improvement on the PASAT was significantly more pronounced in the early treatment group compared with the delayed treatment group after five years, suggesting an effect of early treatment in maintaining an intact cognitive functioning [7]. No cognitive data have been published from the IFNB trials in persons with secondary and primary progressive MS [8-12].

Most of the existing post-marketing observational studies involving interferons and cognition in MS, have been non-randomized, so we should interpreted their results with caution. We are reviewing only studies that have included at least 100 patients.

The effects IFN b-1a on cognitive function in early, mildly disabled RRMS patients were addressed in the Italian multicenter, post-marketing COGIMUS (Cognitive Impairment in Multiple Sclerosis) study [13]. This prospective cohort study included 459 early RRMS patients treated with IFN b-1a s.c. 22 or 44 mcg in everyday clinical practice. The patients were assessed through the Brief Repeatable Neuropsychological Battery (BRNB) and the Stroop test at baseline and at 12 monthly intervals for three years for a total of four cognitive assessments. At baseline there were no differences between the two groups in demographic and clinical characteristics and in the proportions of patients impaired on more than three tests. Data on cognitive performance at baseline and 3 years were available for 318 patients of the original cohort $(72.1 \% ; 22 \mathrm{mcg}, n=153$; $44 \mathrm{mcg}, n=165)$ and showed a $32 \%$ risk reduction of developing impairment in three or more tests for patients on high dose compared with those on the lower dose.
The effect of glatiramer acetate (GA) on cognition was evaluated as part of a phase III trial on RRMS where patients were randomized to receive GA $(20 \mathrm{mg}$ subcutaneously every day) or placebo [14]. Two hundred forty-eight patients were assessed by the BRNB at baseline and after 1-2 years using. Both treatment groups showed a significant improvement in cognitive performance because of "practice effects". The absence of an effect of GA on cognitive profile, could be explain by the low level of baseline cognitive abnormalities and the short-term observation period. No cognitive data have been published in primary progressive MS, although the MSFC was included in a phase III trial of GA [15]. The impact of natalizumab on cognitive profile was investigated in a phase III clinical trials of RRMS patients -the AFFIRM (Natalizumab Safety and Efficacy in Relapsing Remitting Multiple Sclerosis) and SENTINEL (Safety and Efficacy of Natalizumab in Combination with Interferon Beta-1a in Patients with Relapsing Remitting Multiple Sclerosis) $[16,17]$. Both studies showed a positive effect on cognition in all the subjects treated with natalizumab, although the cognitive outcome was evaluated only by the PASAT.

Iaffaldano et al. [18] have examined the effects of natalizumab on cognitive performance in an uncontrolled observational study, by the BRNB and the Stroop test, calculating a global score, defined Cognitive Impairment Index (CII) every 12 months, that allowing the evaluation of changes in cognitive performances independently by the number of cognitive tests failed, using the mean and SD from the normative sample of Rao's battery and the Stroop Test. One hundred and 53 patients completed 1 and 2 year-natalizumab treatment, respectively, at the standard dose of $300 \mathrm{mg}$ every 4 weeks intravenously. After 1 year of treatment the percentage of cognitively impaired patients decreased from $29 \%$ at baseline to $19 \%$ and the mean baseline values of the $\mathrm{CII}$ and fatigue scores were significantly reduced. These significant effects were confirmed in the subgroup of patients treated up to 2 years.

Stephenson et al. [19] have conducted a prospective, uncontrolled study in 333 patients on the effect of natalizumab in patient-reported outcomes measures. After 12 months of pharmacological treatment, $69 \%$ to $88 \%$ of patients reported an improvement in quality of life assessed by the SF-12v2 [20], the MSIS-29 [21], the FS [22], the DS scale [23], fatigue assessed by the MFIS [24] and cognition assessed by the MOS-Cog [25]. Reduction of self-reported fatigue assessed by the Fatigue Scale for Motor and Cognitive functions (FSMC) was also reported in the large uncontrolled TYNERGY study [26, 27].

Although the above studies showed positive influence of natalizumab treatment on cognition, there are limits in the validity of results, due to observational, 
non-randomized studies design and the absence of a control group.

In the FREEDOMS trial, a 24 month, RCT of oral fingolimod compared with placebo in patients with RRMS, a significant effect on the MSFC was observed in both groups compared with the placebo group (Cohen et al., 2010) [28]. Trials on newer oral and biologic DMTs have included the PASAT in the context of the MFSC, although no cognitive results have been published so far.

In conclusion, all these study limitations do not allow to achieve firm conclusions. In fact, the studies with DMTs have shown weak positive effects on cognition and the methodological limitations reduce the strength of the results. The majority of randomized controlled trials on DMT are not appropriate to detect cognitive changes. Cognition is not the primary outcome and often the only explorative measure of cognition is the PASAT, in the context of the MSFC [29]. Observational studies on DMT are non-randomized, have included small sample of patients with different clinical characteristics, used heterogeneous cognitive assessment tools and outcome measures and have not considered the patients' cognitive status at baseline. We can only speculate that early treatment may be the most effective way to preserve intact cognitive functioning and delay the development of cognitive impairment, on the basis of studies focusing on CIS and early RRMS patients. Future trials should assess cognition more systematically, to better understand the potential effect of the new DMT on the patient cognitive performance [1].

\section{Symptomatic drugs}

Due to frequent association between fatigue and cognitive impairment in MS patients and the hypothesis of a shared pathophysiologic basis, it has been speculated that drugs used for the symptomatic management of fatigue in MS may be beneficial also for cognitive functioning [30]. Studies on symptomatic drugs in MS have focused on improving performance in specific, impaired cognitive domains, typically involved in the profile of neuropsychological deficits in MS, such as information processing speed and complex attention or episodic memory. Most of these studies show a few methodological limitations, in particular small sample sizes, the study design, not inclusion of impaired cognition and heterogeneity of cognitive outcomes. The main features of these studies are synthesized in Table 1.

Geisler et al. [31] evaluated 45 MS patients treated with amantadine, pemoline, or placebo for 6 week. Fatigue did not significantly correlate with any of the neuropsychological outcome measures at baseline or after treatment and there were no significant differences in cognitive performance between amantadine, pemoline, and placebo patients. The neuropsychological measures were tests of attention (Digit Span, Trail Making Test, and Symbol Digit Modalities Test), verbal memory (Selective Reminding Test), nonverbal memory (Benton Visual Retention Test), and motor speed (Finger Tapping Test). All groups improved on tests of attention, verbal memory and motor speed, probably due to "practice effects".

Studies with patients treated with modafinil, have done uncertain results. Moller et al. [32] conducted a doubleblind, placebo-controlled randomized trial involving 121 patients with MS and fatigue, finding that modafinil had no great effects on fatigue or cognitive dysfunction. Another study with modafinil suggested a positive treatment effect on other neuropsychological tests, but this study was not placebo-controlled [33]. In a double-blind, placebo-controlled study conducted by Bruce et al. [34], 23 patients with MS had significantly improved delayed memory on a list-learning task after they took modafinil, but no improvement on other cognitive domains or self-reported fatigue. Recently, Ford-Johnson et al. [35] showed no effect of modafinil on learning and memory performance. However, participants showed improvement in working memory task administered, the Wechsler Adult Intelligence Scale-III (WAIS-III) Letter-Number Sequencing task, as compared with those on placebo.

Acetylcholinesterase inhibitors (AChEIs) used in Alzheimer's disease have been tested for improving cognition in other neurological disorders. Specifically, in MS, it is hypothesized that disruption of cholinergic pathways and impaired axonal transport of acetylcholine may produce a reduction of cholinergic drive that might underlie at least in part cognitive dysfunction [1]. Parry et al. [36] have suggested that rivastigmine, a central cholinesterase inhibitor, can perform an acute modulation of potentially adaptive functional changes in cognitive functioning. They studied ten patients with MS and 11 healthy controls using a functional MRI (fMRI) during the execution of Stroop task. All the participants took the drug. In five out of ten MS patients there were a relative normalization of the abnormal Stroop-associated pattern of brain activation, although no change in brain activation was found in any of four healthy controls taking the drug. Cader et al. [37] showed the administration of rivastigmine significantly enhanced fMRI activation in the prefrontal regions for the Stroop task, in a group of 15 MS patients. In this small study, there were no significant changes in the neuropsychological task performance, 11 of 15 patients showed improvements, whereas 4 of 15 patients showed decline. Shaygannejad et al. [38] enrolled 60 MS patients with cognitive impairment in a 3-month single-center, double-blind, placebocontrolled clinical trial. Patients were randomly allocated 
Table 1 Overview of the main studies on symptomatic treatments for cognitive impairment in multiple sclerosis

\begin{tabular}{|c|c|c|c|c|c|}
\hline Authors, year & Drug & Number treated & Design & Duration & Cognitive results \\
\hline Geisler et al., 1996 [31] & Amantadine, pemoline & 16 & $\mathrm{DB}, \mathrm{PC}, \mathrm{RCT}$ & 6 weeks & No improv. \\
\hline Moller et al., 2011 [32] & Modafinil & 62 & $\mathrm{DB}, \mathrm{PC}, \mathrm{RCT}$ & 8 weeks & No improv. \\
\hline Lange et al., 2009 [52] & Modafinil & 8 & $\mathrm{DB}, \mathrm{PC}, \mathrm{RCT}$ & 8 weeks & Improvement \\
\hline Stankoff et al., 2005 [53] & Modafinil & 59 & $\mathrm{DB}, \mathrm{PC}, \mathrm{RCT}$ & 5 weeks & No improv. \\
\hline Wilken et al., 2008 [33] & Modafinil & 23 & $\begin{array}{l}\text { Randomized, } \\
\text { evaluator blind }\end{array}$ & 4 months & Improvement \\
\hline Bruce et al., 2012 [34] & Armodafinil & 16 & $\mathrm{DB}, \mathrm{PC}, \mathrm{CO}$ & 1 week & Improvement \\
\hline Ford-Johnson et al., 2016 [35] & Modafinil & 16 & $\mathrm{DB}, \mathrm{CO}$ & 5 weeks & Improvement \\
\hline Shaygannejad et al. [38] & Rivastigmine & 30 & $\mathrm{DB}, \mathrm{PC}, \mathrm{RCT}$ & 12 weeks & No improvement \\
\hline Parry et al., 2003 [36] & Rivastigmine & 10 & OLT & 4-6 weeks & Improvement \\
\hline Cader et al., 2009 [37] & Rivastigmine & 15 & $\mathrm{CO}, \mathrm{SB}$ & 4-6 weeks & No improv. \\
\hline Krupp et al., 2004 [39] & Donepezil & 35 & $\mathrm{DB}, \mathrm{PC}, \mathrm{RCT}$ & 24 weeks & Improvement \\
\hline Krupp et al., 2011 [40] & Donepezil & 61 & $\mathrm{DB}, \mathrm{PC}, \mathrm{RCT}$ & 24 weeks & No Improv. \\
\hline Lovera et al., 2010 [41] & Memantina & 58 & $\mathrm{DB}, \mathrm{PC}, \mathrm{RCT}$ & 16 weeks & No improv. \\
\hline Villoslada et al., 2009 [54] & Memantina & 19 & $\mathrm{DB}, \mathrm{PC}, \mathrm{CO}$ & 12 months & No improv. \\
\hline Peyro Saint Paul et al., 2016 [42] & Memantina & 50 & $\mathrm{DB}, \mathrm{PC}, \mathrm{PG}, \mathrm{RCT}$ & 52 weeks & No improv. \\
\hline Benedict et al., 2008 [43] & l-amphetamine & 19 & $\begin{array}{l}\text { Counterbalanced, } \\
\text { within-subject }\end{array}$ & $4 x$ single doses & Improvement \\
\hline Morrow et al., 2009 [44] & l-amphetamine & 108 & $\mathrm{DB}, \mathrm{PC}, \mathrm{RCT}$ & 4 weeks & No improv. \\
\hline Sumowki et al., 2011 [45] (re-analysis of 66) & I-amphetamine & 108 & $\mathrm{DB}, \mathrm{PC}, \mathrm{RCT}$ & 4 weeks & Improvement \\
\hline Harel et al., 2009 [46] & Methylphenidate & 14 & $\mathrm{DB}, \mathrm{PC}, \mathrm{RCT}$ & Single dose & Improvement \\
\hline Lovera et al., 2007 [55] & Ginkgo biloba & 20 & $\mathrm{DB}, \mathrm{PC}, \mathrm{RCT}$ & 12 weeks & No improv. \\
\hline Lovera et al., 2012 [56] & Ginkgo biloba & 61 & $\mathrm{DB}, \mathrm{PC}, \mathrm{RCT}$ & 12 weeks & No improv. \\
\hline Johnson et al., 2006 [57] & Ginkgo biloba & 12 & $\mathrm{DB}, \mathrm{PC}, \mathrm{PG}$ & 4 weeks & $\begin{array}{l}\text { Improvement variable } \\
\text { responses }\end{array}$ \\
\hline Magnin et al., 2015 [48] & Fampridine & 50 & OLT & 4 weeks & Improvement \\
\hline Pavsic et al., 2015 [49] & Fampridine & 30 & OLT & 4 weeks & No improv. \\
\hline Jensen et al., 2014 [50] & Fampridine & 108 & OLT & $26-28$ days & Improvement \\
\hline Romero et al., 2015 [47] & Cannabis & 20 & $P G$ & Single dose & No improv. \\
\hline
\end{tabular}

$D B$ double blind, $P C$ placebo controlled, $R C T$ randomized controlled trial, $C O$ crossover, $S B$ single blind, OLT open label trial, $P G$ parallel group

to receive a 12 -week treatment course of either rivastigmine $(1.5 \mathrm{mg}$ once a day increment over 4 weeks to $3 \mathrm{mg}$ twice daily) or placebo. Response to treatment was assessed by the Wechsler Memory Scale (WMS) at baseline and 12 weeks after the start of therapy. They observed a significant memory improvement occurred in both groups, possibly due to "practice effects" and the average WMS general memory score at the end of trial did not change between rivastigmine and placebo group.

The effects of Donepezil on cognitive function in MS have also investigated. Krupp et al. [39] conducted a randomized, double-blind, placebo-controlled, single-center clinical trial of 69 patients with MS who were selected for initial memory difficulties and randomly assigned to receive a 24-week treatment course of either donepezil (10 mg daily) or placebo. Donepezil improved memory performance on the Selective Reminding Test (SRT) when compared with placebo and this benefit remained significant after controlling for several demographic and clinical covariates. Patients in the donepezil group were significantly more likely to self-report memory improvement than those receiving placebo. More recently, Krupp et al. [40], investigated the effects of $10 \mathrm{mg}$ daily of donepezil $(n=61)$ versus $10 \mathrm{mg}$ of placebo $(n=59)$ in 120 cognitively impaired MS patients. After 24 weeks, there were no improvements in memory performance on SRT in the donepezil group, although the subgroup of patients exhibiting more severe degrees of cognitive dysfunction.

Lovera et al. [41] conducted a multicenter doubleblind placebo-controlled clinical trial in MS patients with cognitive impairment. Fifty-eight patients were treated with memantine at $20 \mathrm{mg}$ daily and 68 controls were tested. The results showed that patients treated 
had no improvements in cognitive performance assessed by PASAT and California Verbal Learning Test-II (CVLT-II) Long Delay Free Recall (LDFR). Recently, Peyro Saint Paul et al. [42] conducted a study for examining the efficacy and safety of a long-term administration of memantine as a symptomatic treatment for cognitive disorders in 50 patients. In this double-blind, placebo-controlled, parallel group, randomized trial, the participants were assigned to receive memantine ( $20 \mathrm{mg} /$ day) or a placebo for 52 weeks. No differences between the placebo and memantine groups were observed in the PASAT score, used as primary neuropsychological outcome.

It is reasonable to consider in this overview also CNS stimulants for MS patients and their influence on cognitive profile. In a pilot double-blind, placebo-controlled study involving $19 \mathrm{MS}$ patients [43], single $45 \mathrm{mg}$ doses of L-amphetamine sulfate in MS were associated with improved performance on information processing speed. Morrow et al. [44] tested 151 clinically definite MS patients randomized to L-amphetamine or to placebo in a 6-week. The trial results did not confirm any significant improvement on Symbol Digit Modalities Test (SDMT) or on the subjective ratings of cognition. In a re-analysis of the study conducted by Sumowski et al. [45], the Authors suggested the drug may act by improving hippocampal function. In fact, there was a significant effect of L-amphetamine sulfate on auditory/verbal and visual/ spatial memory in the cognitively impaired MS patients. Harel et al. studied the effect of methylphenidate on 26 MS patients with impaired attention in a double-blind placebo-controlled trial [46]. The patients were randomized to receive a single dose of $10 \mathrm{mg}$ methylphenidate or placebo. Attention was assessed using PASAT-3" and PASAT-2" at baseline and one hour after drug/placebo administration. Methylphenidate significantly improved performance of both PASAT-3" and PASAT-2" tests by 22.8 and $25.6 \%$ respectively, while no significant changes were observed in placebo treated patients.

Recently the use of the cannabis has been approved for the symptomatic treatment of spasticity. Romero et al. [47] conducted a study on the effect of cannabis on cognition. They examined 20 MS patients who smoke cannabis for symptom relief, and 19 matched noncannabis-smoking MS patients. Patients were evaluated by the BRNB and structural MRI scans. Results showed that decreased regional brain volume was associated with poorer performance on all neuropsychological tests in MS patients who smoked cannabis. Specially cannabissmoking MS patients showed significantly lower performance on the 10/36 spatial recall test and the PASAT.

Few studies have preliminarily explored the impact of fampridine (4-aminopyridine) on motor and cognitive parameters. Results from a trial conducted by
Magnin et al. [48] with 50 MS patients, showed that verbal fluencies were significantly improved after fampridine treatment. Pavsic et al. [49] conducted a nonrandomized study including 30 patients with different types of MS, treated with $10 \mathrm{mg}$ of fampridine twice daily. They obtained a gait performance of $56.7 \%$ and after 28 days of treatment, significant improvement among responders occurred in total MSFC score. However, there was no statistically significant improvement of PASAT.

Jensen et al. performed another open-label study of $108 \mathrm{MS}$ patients treated with fampridine $10 \mathrm{mg}$ BID. After 26-28 days of treatment, results showed significant improvements on quantitative tests of upper and lower limb functions as well as the SDMT [50].

We can summarize that, taking together, all these weak results do not support the use of any of the above symptomatic drugs for improving MS-related cognitive impairments.

\section{Conclusions}

Over the past two decades MS-related cognitive dysfunction has received growing attention. Validated brief and extensive batteries for the neuropsychological assessment of MS patients are now available [1]. The approach to cognitive assessment should be extensive, taking into account possible confounding factors. Among these, fatigue, depression, comorbidities and also the possible harmful effect of symptomatic medications on cognition, such as benzodiazepines, antiepileptic drugs, anticholinergic drugs used for bladder dysfunction [1].

Despite the great availability of pharmacological drugs for reducing disease activity in MS, no effective symptomatic treatment has been established for cognitive impairment. The results of studies are inconsistent or negative and the few positive findings have not been confirmed in successive trials. Pharmacological therapies of comorbidities that can contribute to poor cognitive performance, such as depression or fatigue, may also provide cognitive benefits, but currently there are not consistent evidences in this area. The use of cognitive enhancer agents could have a positive effect in contrasting the side effects of other drugs (such as benzodiazepines, baclofen, alpha lytic, etc.) which are currently used to treat other participating symptoms. The research in this field must be considered preliminary. The findings that we already have are controversial and not sufficiently strong to currently recommend the clinical use of these classes of medications for treating CI. Further studies in this field could combine older and newer pharmacological strategies with cognitive rehabilitation and, possibly, physical exercise [51]. 


\section{Abbreviations}

AchEIS: Acetylcholinesterase inhibitors; AFFIRM: Natalizumab safety and efficacy in relapsing remitting multiple sclerosis; BRNB: Brief repeatable neuropsychological battery; Cl: Cognitive impairment; Cll: Cognitive impairment index; CIS: Clinically isolated syndrome; COGIMUS: Cognitive impairment in multiple sclerosis; CVLT-II: California Verbal Learning Test-II; DMT: Disease modifying treatment; DS: Disease step; fMRI: Functional magnetic resonance imaging; FS: Functional status; FSMC: Fatigue scale for motor and cognitive functions; GA: Glatiramer acetato; LDFR: Long delay free recall; MFIS: Modified fatigue impact scale; MOS-Cog: Medical outcome scale cognitive functioning; MS: Multiple sclerosis; MSFC: Multiple sclerosis functional composite; MSIS-29: Multiple sclerosis impact scale; PASAT: Paced auditory serial addition test; RRMS: Relapsing remitting multiple sclerosis; SDMT: Symbol digit modalities test; SENTINEL: Safety and Efficacy of Natalizumab in Combination with Interferon Beta-1a in Patients with Relapsing Remitting Multiple Sclerosis; SF-12v2: Short form 12 version 2; SRT: Selective reminding test; WAIS-III: Wechsler Adult Intelligence Scale-III; WMS: Wechsler memory scale; BENEFIT: (Betaferon/Betaseron in Newly Emerging MS for Initial Treatment)

\section{Acknowledgements}

Not applicable.

\section{Funding}

Not applicable.

\section{Availability of data and materials}

Data sharing is not applicable to this article as no datasets were generated or analysed during the current study.

\section{Authors' contributions}

All authors wrote the manuscript. MPA drafted/revised the manuscript. All authors read and approved the final manuscript.

\section{Competing interests}

$\mathrm{CN}$ and $\mathrm{BG}$ have no competing interests. MPA received grants/research supports from Biogen, Teva, Merck Serono, Novartis; received honoraria from Merck Serono, Biogen, Teva, Novartis, Almirall.

\section{Consent for publication}

Not applicable.

\section{Ethics approval and consent to participate}

Not applicable.

\section{Publisher's Note}

Springer Nature remains neutral with regard to jurisdictional claims in published maps and institutional affiliations.

\section{Received: 1 February 2017 Accepted: 21 April 2017}

Published online: 05 June 2017

\section{References}

1. Amato MP, Langdon D, Montalban X, Benedict RH, DeLuca J, Krupp LB, et al. Treatment of cognitive impairment in multiple sclerosis: position Paper. J Neurol. 2013;260(6):1452-68.

2. Gold R, Wolinsky JS, Amato MP, Comi G. Evolving expectations around early management of multiple sclerosis. Ther Adv Neurol Disord. 2010;3(6):351-67.

3. Fischer JS, Priore RL, Jacobs LD, Cookfair DL, Rudick RA, Herndon RM, et al Neuropsychological effects of interferon beta-1a in relapsing multiple sclerosis. Multiple Sclerosis Collaborative Research Group. Ann Neurol. 2000; 48:885-92

4. Kappos L, Polman CH, Freedman MS, Edan G, Hartung HP, Miller DH, et al. Treatment with interferon beta-1b delays conversion to clinically definite and McDonald MS in patients with clinically isolated syndromes. Neurology. 2006;67(7):1242-9.

5. Kappos L, Freedman MS, Polman CH, Montalbán X, Hartung HP, Hemmer B, et al. Effect of early versus delayed interferon beta- $1 \mathrm{~b}$ treatment on disability after a first clinical event suggestive of multiple sclerosis: a 3-year follow-up analysis of the BENEFIT study. Lancet. 2007;370(9585):389-97.
6. Kappos L, Freedman MS, Polman CH, Kappos L, Freedman MS, Polman CH, et al. Long-term effect of early treatment with interferon beta-1b after a first clinical event suggestive of multiple sclerosis: 5-year active treatment extension of the phase 3 BENEFIT trial. Lancet Neurol. 2009; 8(11):987-97.

7. Penner IK, Stemper B, Calabrese P, Freedman MS, Polman CH, Edan G, et al. Effects of interferon beta-1b on cognitive performance in patients with a first event suggestive of multiple sclerosis. Mult Scler. 2012;18(10):1466-71.

8. Kappos L, Polman C, Pozzilli C, Thompson A, Beckmann K, Dahlke F. European Study Group in Final analysis of the European multicenter trial on IFNbeta-1b in secondary-progressive MS Interferon beta-1b in SecondaryProgressive MS. Neurology. 2001;57(11):1969-75.

9. Panitch H, Miller A, Paty D, Weinshenker B. North American Study Group on Interferon beta-1b in Secondary Progressive MS Interferon beta-1b in secondary progressive MS: results from a 3-year controlled study. Neurology. 2004;63(10):1788-95.

10. Cohen JA, Cutter GR, Fischer JS, Goodman AD, Heidenreich FR, Kooijmans MF, et al. Benefit of interferon beta-1a on MSFC progression in secondary progressive MS. Neurology. 2002;59:679-87.

11. Leary SM, Miller DH, Stevenson VL, Brex PA, Chard DT, Thompson AJ. Interferon beta-1a in primary progressive MS: an exploratory, randomize Cohen, J.d, controlled trial. Neurology. 2003;60(1):44-51.

12. Montalban X, Sastre-Garriga J, Filippi M, Khaleeli Z, Téllez N, Vellinga MM. Primary progressive multiple sclerosis diagnostic criteria: a reappraisal. Mult Scler. 2009;15(12):1459-65.

13. Patti F, Amato MP, Bastianello S, Caniatti L, Di Monte E, Ferrazza P, et al Effects of immunomodulatory treatment with subcutaneous interferon beta-1a on cognitive decline in mildly disabled patients with relapsingremitting multiple sclerosis. Mult Scler. 2010;16:68-77.

14. Weinstein A, Scwid SI, Schiffer RB, McDermott MP, Giang DW, Goodman AD. Neuropsychologic status in multiple sclerosis after treatment with glatiramer. Arch Neurol. 1999;56:319-24.

15. Wolinsky JS, Narayana PA, O'Connor P, Coyle PK, Ford C, Johnson K, et al. Glatiramer acetate in primary progressive multiple sclerosis: results of a multinational, multicenter, double-blind, placebo-controlled trial. Ann Neurol. 2007:61(1):14-24.

16. Polman CH, O'Connor PW, Havrdova E, Hutchinson M, Kappos L, Miller DH, et al. A randomized, placebo-controlled trial of natalizumab for relapsing multiple sclerosis. N Engl J Med. 2006;354(9):899-910.

17. Rudick RA, Stuart WH, Calabresi PA, Confavreux C, Galetta SL, Radue EW, et al. Natalizumab plus interferon beta-1a for relapsing multiple sclerosis. $\mathrm{N}$ Engl J Med. 2006;354(9):911-23.

18. Iaffaldano P, Viterbo RG, Paolicelli D, Lucchese G, Portaccio E, Goretti B, et al Impact of natalizumab on cognitive performances and fatigue in relapsing multiple sclerosis: a prospective, open-label, two years observational study. PLoS One. 2012;7(4):e35843.

19. Stephenson JJ, Kern DM, Agarwal SS, Zeidman R, Rajagopalan K, Kamat SA et al. Impact of natalizumab on patient-reported outcomes in multiple sclerosis: a longitudinal study. Health Qual Life Outcomes. 2012;27:155.

20. Ware Jr J, Kosinski M, Keller SD. A 12-Item Short-Form Health Survey: construction of scales and preliminary tests of reliability and validity. Med Care. 1996;34(3):220-33.

21. Hobart J, Lamping D, Fitzpatrick R, Riazi A, Thompson A. The Multiple Sclerosis Impact Scale (MSIS-29): a new patient-based outcome measure. Brain. 2001;124(Pt 5):962-73.

22. Goodin DS. A questionnaire to assess neurological impairment in multiple sclerosis. Mult Scler. 1998;4(5):444-51.

23. Hohol MJ, Orav EJ, Weiner HL. Disease steps in multiple sclerosis: a simple approach to evaluate disease progression. Neurology. 1995;45(2):251-5.

24. Stewart AL, Ware JE. Measuring functioning and well-being: the medical outcomes study approach. Durham: Duke University Press; 1992.

25. Ritvo PG. The Consortium of Multiple Sclerosis Centers Health Services Research Subcommittee. MSQLI Multiple Sclerosis Quality of Life Inventory: a user's manual. New York: National Multiple Sclerosis Society; 1997.

26. Penner IK, Sivertsdotter EC, Celius EG, Fuchs S, Schreiber K, Berkö S. et al., TYNERGY trial investigators.Improvement in Fatigue during Natalizumab Treatment is Linked to Improvement in Depression and Day-Time Sleepiness. Front Neurol. 2015;23(6):18.

27. Svenningsson A, Falk E, Celius EG, Fuchs S, Schreiber K, Berkö S, et al. Natalizumab treatment reduces fatigue in multiple sclerosis. Results from the TYNERGY trial; a study in the real life setting. PLoS One. 2013;8(3):e58643. 
28. Cohen JA, Barkhof F, Comi G, Hartung HP, Khatri BO, Montalban X, et al. Oral fingolimod or intramuscular interferon for relapsing multiple sclerosis N Engl J Med. 2010;362(5):402-15.

29. Rudick R, Antel J, Confavreux C, Cutter G, Ellison G, Fischer J, et al. Recommendations from the national multiple sclerosis society clinical outcomes assessment task force. Ann Neurol. 1997:42:379-82.

30. Tur C. Fatigue management in multiple sclerosis. Curr Treat Options Neurol. 2016;18(6):26.

31. Geisler MW, Sliwinski M, Coyle PK, Masur DM, Doscher C, Krupp LB. The effects of amantadine and pemoline on cognitive functioning in multiple sclerosis. Arch Neurol. 1996;53(2):185-8.

32. Moller F, Poettgen J, Broemel F, Neuhaus A, Daumer M, Heesen C. HAGIL (Hamburg Vigil Study): a randomized placebo-controlled double-blind study with modafinil for treatment of fatigue in patients with multiple sclerosis. Mult Scler. 2011:17(8):1002-9.

33. Wilken JA, Sullivan C, Wallin M, Rogers C, Kane RL, Rossman H, et al. Treatment of multiple sclerosis-related cognitive problems with adjunctive modafinil: rationale and preliminary supportive data. Int J MS Care. 2008;10:1-10.

34. Bruce J, Hancock L, Roberg B, Brown A, Henkelman E, Lynch S. Impact of armodafinil on cognition in multiple sclerosis: a randomized, double-blind crossover pilot study. Cogn Behav Neurol. 2012:25(3):107-14.

35. Ford-Johnson L, DeLuca J, Zhang J, Elovic E, Lengenfelder J, Chiaravalloti ND. Cognitive effects of modafinil in patients with multiple sclerosis: A clinical trial. Rehabil Psychol. 2016;61(1):82-91.

36. Parry AM, Scott RB, Palace J, Smith S, Matthews PM. Potentially adaptive functional changes in cognitive processing for patients with multiple sclerosis and their acute modulation by rivastigmine. Brain. 2003;126(Pt 12):2750-60.

37. Cader S, Palace J, Matthews PM. Cholinergic agonism alters cognitive processing and enhances brain functional connectivity in patients with multiple sclerosis. J Psychopharmaco. 2009;23(6):686-96.

38. Shaygannejad V, Janghorbani M, Ashtari F, Zanjani HA, Zakizade N. Effects of rivastigmine on memory and cognition in multiple sclerosis. Can J Neurol Sci. 2008;35(4):476-81.

39. Krupp LB, Christodoulou C, Melville P, Scherl WF, MacAllister WS, Elkins LE. Donepezil improved memory in multiple sclerosis in a randomized clinical trial. Neurology. 2004;63:1579-85.

40. Krupp LB, Christodoulou C, Melville P, Scherl WF, Pai L-Y, Muenz LR, et al. Multicenter randomized clinical trial of donepezil for memory impairment in multiple sclerosis. Neurology. 2011;76:1500-7.

41. Lovera JF, Frohman E, Brown TR, Bandari D, Nguyen L, Yadav V, et al. Memantine for cognitive impairment in multiple sclerosis: a randomized placebo-controlled trial. Mult Scler. 2010;16(6):715-23.

42. Peyro Saint Paul L, Creveuil C, Heinzlef O, De Seze J, Vermersch P, Castelnovo G, et al. Efficacy and safety profile of memantine in patients with cognitive impairment in multiple sclerosis: A randomized, placebocontrolled study. J Neurol Sci. 2016;363:69-76.

43. Benedict RH, Munschauer F, Zarevics P, Erlanger D, Rowe V, Feaster T, et al, Effects of $\mathrm{L}$-amphetamine sulfate on cognitive function in multiple sclerosis patients. J Neurol. 2008;255:848-52.

44. Morrow SA, Kaushik T, Zarevics P, Erlanger D, Mark F, Munschauer BE, et al. The effects of L-amphetamine sulfate on cognition in MS patients: results of a randomized controlled trial. J Neurol. 2009;256:1095-102.

45. Sumowski JF, Chiaravalloti N, Erlanger D, Kaushik T, Benedict RH, Deluca J. Lamphetamine improves memory in MS patients with objective memory impairment. Mult Scler. 2011;17(9):988. 1141-45.

46. Harel Y, Appleboim N, Lavie M, Achiron A. Single dose of methylphenidate improves cognitive performance in multiple sclerosis patients with impaired attention process. J Neurol Sci. 2009;15:38-40.

47. Romero K, Pavisian B, Staines WR, Feinstein A. Multiple sclerosis, cannabis and cognition: A structural MRI study. Neuroimage Clin. 2015;9(8):140-7.

48. Magnin E, Sagawa Jr Y, Chamard L, Berger E, Moulin T, Decavel P. Verbal fluencies and fampridine treatment in multiple sclerosis. Eur Neurol. 2015; 74:243-50

49. Pavsic K, Pelicon $\mathrm{K}$, Ledinek AH, Sega S. Short-term impact of fampridine on motor and cognitive functions, mood and quality of life among multiple sclerosis patients. Clin Neurol Neurosurg. 2015;139:35-40.

50. Jensen H, Ravnborg M, Mamoei S, Dalgas U, Stenager E. Changes in cognition, arm function and lower body function after slow-release Fampridine treatment. Mult Scler. 2014;20(14):1872-80.

51. Feinstein $A$, Dalgas $U$. The benefits of exercise in progressive MS: some cautious optimism. Mult Scler. 2014;20(3):269-70.
52. Lange $\mathrm{R}$, Volkmer M, Heesen $\mathrm{C}$, Liepert J. Modafinil effects in multiple sclerosis patients with fatigue. J Neurol, 2009;256:645-50.

53. Stankoff B, Waubant E, Confavreux C, Edan G, Debouverie M, Rumbach L, et al. Modafinil for fatigue in MS: a randomized placebo-controlled double-blind study. Neurology. 2005;64:1139-43.

54. Villoslada P, Arrondo G, Sepulcre J, Alegre M, Artieda J. Memantine induces reversible neurologic impairment in patients with MS. Neurology. 2009; 72(19):1630-3.

55. Lovera J, Bagert B, Smoot K, Morris CD, Frank R, Bogardus K, et al. Ginkgo biloba for the improvement of cognitive performance in multiplesclerosis: a randomized, placebo-controlled trial. Mult Scler. 2007:13:376-85.

56. Lovera JF, Kim E, Heriza E, Fitzpatrick M, Hunziker J, Turner AP, Adams J, et al. Ginkgo biloba does not improve cognitive function in MS: a randomized placebo-controlled trial. Neurology. 2012;79(12):1278-84.

57. Johnson SK, Diamond BJ, Rausch S, Kaufman M, Shiflett SC, Graves L. The effect of Ginkgo biloba on functional measures in multiple sclerosis: a pilot randomized controlled trial. Explore (NY). 2006;2:19.

\section{Submit your next manuscript to BioMed Central and we will help you at every step:}

- We accept pre-submission inquiries

- Our selector tool helps you to find the most relevant journal

- We provide round the clock customer support

- Convenient online submission

- Thorough peer review

- Inclusion in PubMed and all major indexing services

- Maximum visibility for your research

Submit your manuscript at www.biomedcentral.com/submit
) Biomed Central 